\title{
Video Article \\ Isolation of Intermediate Filament Proteins from Multiple Mouse Tissues to Study Aging-associated Post-translational Modifications
}

\author{
Rachel A. Battaglia ${ }^{1}$, Parijat Kabiraj ${ }^{1}$, Helen H. Willcockson ${ }^{1}$, Melinda Lian ${ }^{1}$, Natasha T. Snider ${ }^{1}$ \\ ${ }^{1}$ Department of Cell Biology and Physiology, School of Medicine, University of North Carolina at Chapel Hill
}

Correspondence to: Natasha T. Snider at natasha_snider@med.unc.edu

URL: https://www.jove.com/video/55655

DOI: doi:10.3791/55655

Keywords: Biochemistry, Issue 123, intermediate filaments, post-translational modification, mass spectrometry, immunoprecipitation, aging, stress, animal models, tissue fractionation

Date Published: 5/18/2017

Citation: Battaglia, R.A., Kabiraj, P., Willcockson, H.H., Lian, M., Snider, N.T. Isolation of Intermediate Filament Proteins from Multiple Mouse Tissues to Study Aging-associated Post-translational Modifications. J. Vis. Exp. (123), e55655, doi:10.3791/55655 (2017).

\section{Abstract}

Intermediate filaments (IFs), together with actin filaments and microtubules, form the cytoskeleton - a critical structural element of every cell. Normal functioning IFs provide cells with mechanical and stress resilience, while a dysfunctional IF cytoskeleton compromises cellular health and has been associated with many human diseases. Post-translational modifications (PTMs) critically regulate IF dynamics in response to physiological changes and under stress conditions. Therefore, the ability to monitor changes in the PTM signature of IFs can contribute to a better functional understanding, and ultimately conditioning, of the IF system as a stress responder during cellular injury. However, the large number of IF proteins, which are encoded by over 70 individual genes and expressed in a tissue-dependent manner, is a major challenge in sorting out the relative importance of different PTMs. To that end, methods that enable monitoring of PTMs on IF proteins on an organism-wide level, rather than for isolated members of the family, can accelerate research progress in this area. Here, we present biochemical methods for the isolation of the total, detergent-soluble, and detergent-resistant fraction of IF proteins from 9 different mouse tissues (brain, heart, lung, liver, small intestine, large intestine, pancreas, kidney, and spleen). We further demonstrate an optimized protocol for rapid isolation of IF proteins by using lysing matrix and automated homogenization of different mouse tissues. The automated protocol is useful for profiling IFs in experiments with high sample volume (such as in disease models involving multiple animals and experimental groups). The resulting samples can be utilized for various downstream analyses, including mass spectrometry-based PTM profiling. Utilizing these methods, we provide new data to show that IF proteins in different mouse tissues (brain and liver) undergo parallel changes with respect to their expression levels and PTMs during aging.

\section{Video Link}

The video component of this article can be found at https://www.jove.com/video/55655/

\section{Introduction}

IFs are a family of proteins that in humans are encoded by 73 genes and categorized into six major types: types I-IV are cytoplasmic (e.g. epithelial and hair keratins (K), myocyte desmin, neurofilaments, glial fibrillary acidic protein (GFAP), and others); type $V$ are the nuclear lamins; and type VI are IFs in the eye lens ${ }^{1}$. In terms of their molecular organization, IF proteins have three common domains: a highly conserved coiledcoil "rod" domain, and globular "head" and "tail" domains. IF protein tetramers assemble to form short filament precursors, which are ultimately incorporated into mature filaments that shape dynamic cytoskeletal and nucleoskeletal structures involved in mechanical protection ${ }^{2}$, stress sensing $^{3,4}$, regulation of transcription ${ }^{5}$ and growth, and other critical cellular functions ${ }^{1,6,7}$.

The functional importance of the IF system is highlighted by the existence of many human diseases caused by missense mutations in IF genes, including neuropathies, myopathies, skin fragility disorders, metabolic dysfunctions, and premature aging syndromes ${ }^{8}$. Some IF gene mutations do not cause, but predispose their carriers to disease progression, such as the simple epithelial keratins in liver disease ${ }^{9}$. The latter is due to the critical stress-protective functions of IFs in epithelia. IFs in general are among the most abundant cellular proteins under basal conditions, but are further strongly induced during various types of stress ${ }^{10}$. For example, recent studies evaluating proteome-wide changes in the nematode C. elegans demonstrated that multiple IFs are highly upregulated and prone to aggregation during organismal aging ${ }^{11,12}$. Since maintenance of a proper IF structure is essential for cellular resistance to various forms of stress ${ }^{10}$, IF aggregation may also contribute to the functional decline during aging. However, organismal-level studies examining multiple mammalian IF proteins across different tissues undergoing stress are lacking.

IFs are highly dynamic structures that adapt to meet cellular demands. Keratins, for example, undergo a biosynthesis-independent cycling between soluble (non-filamentous) and insoluble (filamentous) protein pool ${ }^{13}$. Under normal physiologic conditions approximately $5 \%$ the total $\mathrm{K} 8 / \mathrm{K} 18$ pool can be extracted in detergent-free buffer, in comparison to approximately $20 \%$ that can be solubilized in the non-ionic detergent Nonidet P-40, which is biochemically comparable to Triton-X100 ${ }^{14,15}$. During mitosis there is a notable increase in the solubility of simple-type epithelial $\mathrm{K} 8$ and $\mathrm{K}_{18}{ }^{14}$, which is less apparent in epidermal keratins but more apparent in vimentin and other type III IF proteins ${ }^{15,16}$. Solubility 
properties of IF proteins are tightly regulated by phosphorylation, a key post-translational modification (PTM) for filament rearrangement and solubility $^{17,18,19,20}$. Most IFs undergo extensive regulation by a number of PTMs at conserved sites, resulting in functional changes ${ }^{17}$.

The purpose of this method is to introduce investigators who are new to the IF field to biochemical extraction and analytical methods for the study of IF proteins across multiple mouse tissues. Specifically, we focus on isolation of IF proteins using a high-salt extraction method and assessment of changes in PTMs via mass-spectrometry and by PTM-targeting antibodies. These methods build upon previously published procedures ${ }^{21}$ but include modifications for extracting different IF protein types to uncover common mechanism for regulation across the IF family. For example, K8 acetylation at a specific lysine residue regulates filament organization, while hyperacetylation promotes K8 insolubility and aggregate formation ${ }^{22}$. Recent global proteomic profiling studies have additionally revealed that most tissue-specific IF proteins are also targets for acetylation and that most IF acetylation sites are confined to the highly conserved rod domain. This highlights the need for methods suitable for global profiling of the IF system. We also introduce a rapid method of isolating IF proteins from multiple tissues using automated homogenization in optimized lysing matrix. The resulting preparations are suitable for downstream PTM analysis via mass spectrometry and other methods.

Protocol

The protocol is approved and performed in accordance with the Institutional Animal Care and Use Committee (IACUC) at the University of North Carolina.

\section{Preparations}

1. Prepare Triton- $X$ buffer ( $1 \%$ Triton $X-100,5 \mathrm{mM}$ ethylenediaminetetraacetic acid (EDTA), bring up volume in phosphate-buffered saline (PBS), pH 7.4). To make $500 \mathrm{~mL}$ : stir $5 \mathrm{~mL}$ each of Triton X-100 and $500 \mathrm{mM}$ EDTA into $490 \mathrm{~mL}$ of PBS, pH 7.4. Store Triton-X buffer solution at $4{ }^{\circ} \mathrm{C}$.

2. Prepare High Salt Buffer (10 mM Tris- $\mathrm{HCl}, \mathrm{pH} 7.6,140 \mathrm{mM} \mathrm{NaCl}, 1.5 \mathrm{M} \mathrm{KCl}, 5 \mathrm{mM}$ EDTA, $0.5 \%$ Triton $\mathrm{X}-100$, bring up volume in double distilled (dd) $\mathrm{H}_{2} \mathrm{O}$ ). To make $500 \mathrm{~mL}$ : stir $10 \mathrm{~mL}$ of $0.5 \mathrm{M} \mathrm{Tris-HCl}(\mathrm{pH} 7.6), 14 \mathrm{~mL}$ of $5 \mathrm{M} \mathrm{NaCl}, 55.9 \mathrm{~g} \mathrm{KCl}, 5 \mathrm{~mL}$ of $0.5 \mathrm{M} \mathrm{EDTA}$, and $2.5 \mathrm{~mL}$ of Triton X-100, adjust volume to $500 \mathrm{~mL}$ using double distilled water). Store High Salt Buffer solution at $4{ }^{\circ} \mathrm{C}$.

3. Just prior to use, supplement an appropriate amount of Triton-X and High Salt Buffer (e.g. $1 \mathrm{~mL}$ for each $25 \mathrm{mg}$ tissue sample) with a protease or protease/phosphatase inhibitor cocktail and discard any unused buffer containing the inhibitors.

4. Prepare $5 \mathrm{mM}$ EDTA in 1x PBS, pH 7.4. To make $500 \mathrm{~mL}$ : stir $5 \mathrm{~mL}$ of $0.5 \mathrm{M}$ EDTA into $495 \mathrm{~mL}$ of $1 \times$ PBS, pH 7.4.

5. Isolate different mouse organs (brain, heart, lung, liver, pancreas, colon, intestine, kidney, spleen) using approved protocols that comply with veterinary guidelines and institutional standards ${ }^{23}$. The tissue collection procedure should take no more than 5 min to preserve RNA and protein integrity of protease-rich tissues (e.g. pancreas should be processed first).

6. Cut a small amount of tissue $(\sim 5-20 \mathrm{mg})$ and place in RNA storage solution, for subsequent RNA extraction, cDNA synthesis, and quantitative real-time PCR analysis for IF gene expression. Place RNA storage solution tubes with tissue at $4{ }^{\circ} \mathrm{C}$ overnight and follow manufacturer protocol for further storage and isolation steps.

7. Cut the rest of the tissue into smaller fragments $(e . g .0 .5 \mathrm{~cm})$ and place in cryovial. Snap-freeze and store vials at $-80^{\circ} \mathrm{C}$ or liquid nitrogen for longer term storage.

\section{IF Gene Expression Analysis}

1. Extract RNA from tissues preserved in the RNA storage solution reagent. Use any suitable/preferred RNA extraction method according to manufacturer's protocol.

2. Quantify RNA concentration and use $2 \mu \mathrm{g}$ of RNA to generate cDNA using a suitable reverse transcription kit according to manufacturer's protocol.

3. Using the generated cDNA and mouse IF gene-specific primers set up qPCR reactions, including three technical replicates of each sample as well as blank control according to manufacturer's protocol.

4. Quantify IF gene expression as fold change comparing different conditions (e.g. young versus old tissue).

\section{Preparation of Total Tissue Lysates for Immunoblot}

1. Homogenize $25 \mathrm{mg}$ of tissue in $1 \mathrm{~mL}$ of $2 \mathrm{x}$ non-reducing SDS sample buffer. Omit bromophenol blue dye from the sample buffer if a colorimetric protein assay is to be performed to quantify protein concentration.

2. Add $5 \%(\mathrm{v} / \mathrm{v})$ of 2-mercaptoethanol (2-ME) to make reduced samples. To $200 \mu \mathrm{L}$ of the non-reducing samples, add $10 \mu \mathrm{L}$ of $2-\mathrm{ME}$.

3. Determine protein concentration using detergent- and reducing agent-compatible protein assay. If dye is already included in the sample buffer, the protein amount can be estimated after running a gel via a number of techniques, including Coomassie-based stain ${ }^{24}$.

4. Vortex all samples and heat at $95^{\circ} \mathrm{C}$ for $5 \mathrm{~min}$.

5. Perform western blotting under both reducing and non-reducing conditions. Exposure membrane briefly $(<1$ min) to reveals monomeric species, and longer (>1 min) to reveal high molecular mass complexes containing IF proteins. If monitoring aggregation, examine entire gel/ membrane (including the bottoms of the gel wells).

6. Run a parallel gel and stain with a protein stain as a loading control ${ }^{24}$. In disease models or injury experiments total protein stain should be used as a loading control, as opposed to immunoblots for 'housekeeping' proteins (e.g. actin, GAPDH) because the latter change under different stress conditions.

\section{Preparation of Detergent-soluble and High-salt Extracts of Tissue-specific IFs}

1. Add $1 \mathrm{~mL}$ of ice-cold Triton $\mathrm{X}-100$ buffer into a glass tube homogenizer and place it on ice. 
2. Remove a small piece of tissue $(\sim 25 \mathrm{mg})$ from liquid nitrogen storage and place directly into the glass homogenizer. Use a polytetrafluoroethylene pestle to homogenize (50 strokes) and avoid making bubbles. Keep the homogenizer and lysate cold at all times.

3. Transfer lysate to a $1.5 \mathrm{~mL}$ microcentrifuge tube on ice and centrifuge at $20,000 \times \mathrm{g}$ for $10 \mathrm{~min}$ in a pre-chilled centrifuge $\left(4{ }^{\circ} \mathrm{C}\right)$.

4. Collect the supernatant fraction into a separate tube. This is the Triton X-soluble fraction, which can be used for immunoprecipitation (i.p.) and analysis of the detergent-soluble pool of IF proteins. Note that steps 4.1-4.4 may be repeated to achieve a cleaner IF extract from brain tissue.

5. Add $1 \mathrm{~mL}$ of High Salt Buffer to the tissue pellet, transfer to a clean homogenizer and dounce 100 strokes. Transfer the homogenate back to the microcentrifuge tube and place the tube on a rotating shaker in the cold room for $1 \mathrm{~h}$.

6. Centrifuge the homogenates at $20,000 \times \mathrm{g}$ for $20 \mathrm{~min}$ at $4{ }^{\circ} \mathrm{C}$. Discard the supernatant.

7. Add $1 \mathrm{~mL}$ of ice-cold PBS/EDTA buffer to the pellet and homogenize the pellet (20 strokes) in a clean homogenizer as a final clean-up step* Transfer to a new tube and centrifuge at $20,000 \times \mathrm{g}$ for $10 \mathrm{~min}$ at $4{ }^{\circ} \mathrm{C}$ to obtain the IF protein-rich high salt extract (HSE). * Optionally, vortex instead of homogenization at this step.

8. Discard the supernatant and dissolve the pellets in $300 \mu \mathrm{L}$ of non-reducing SDS sample buffer that has been pre-heated. Break up the pellet initially by pipetting and vortexing, and then heat the samples for 5 min at $95{ }^{\circ} \mathrm{C}$.

9. Vortex and pipet as needed to ensure the pellet is dissolved. It may take several minutes to fully dissolve the pellets.

10. Store all samples at $-20^{\circ} \mathrm{C}$ until analysis.

\section{Automated Tissue Lysis for IF Protein Extraction in High-volume Experiments}

1. For RNA extraction, place lysis buffer (600 $\mu \mathrm{L}$ buffer per $25 \mathrm{mg}$ of tissue) in a tube containing lysing matrix $\mathrm{D}$ (uses small ceramic spheres) and pulse twice for $25 \mathrm{~s}$ in the tissue lyser. Separate lysate from the matrix by centrifugation at $20,000 \mathrm{xg}$ and proceed to the next step in isolation.

2. For protein extraction, place Triton $X-100$ (or SDS sample buffer if preparing total lysate) in a lysing tube with lysing matrix SS (use a single stainless steel bead). After testing multiple matrices, this was selected because it produces IF protein extracts that are in similar quality as the traditional douncing method. Note that the automated method is not optimal for pancreas and spleen, and the standard homogenization protocol should be used for these tissues.

3. To proceed with preparation of High Salt Extract, remove the stainless steel bead from the tube using a magnet, and centrifuge the tubes at $20,000 \times \mathrm{g}$ for $10 \mathrm{~min}$ at $4^{\circ} \mathrm{C}$

4. Continue with step 4.4 (above) of the manual protocol.

5. Store all samples at $-20^{\circ} \mathrm{C}$ until analysis.

\section{Immuno-enrichment of Post-translationally Modified IF Proteins}

1. Prepare PBST buffer (0.02\% Tween-20 in PBS). To make $50 \mathrm{~mL}$, add $10 \mu \mathrm{L}$ of Tween-20 to $50 \mathrm{~mL}$ of PBS, $\mathrm{pH} 7.4$.

2. Prepare PTM antibody solution (1-10 $\mu \mathrm{g}$ of antibody in $200 \mu \mathrm{L}$ of PBST). In general, $3 \mu \mathrm{g}$ of antibody/reaction is a good starting condition that can be further optimized if needed.

3. For each reaction, aliquot $50 \mu \mathrm{L}$ of magnetic beads into a microcentrifuge tube, place on the magnet and aspirate the bead storage solution.

4. Conjugate the beads to the immunoprecipitation antibody by re-suspending in the antibody solution and incubating on rotator (end-over-end, to ensure mixing of small volumes) at room temperature for $20 \mathrm{~min}$.

5. Place the tubes on magnet and aspirate antibody solution.

6. Rinse the antibody-conjugated beads once in $200 \mu \mathrm{L}$ PBST and remove wash buffer.

7. Add $0.6-1 \mathrm{~mL}$ of the tissue lysate to the beads, mix by gentle pipetting and incubate for $3 \mathrm{~h}$ on rotator in a cold room.

8. Place tubes on magnet, remove lysate, and wash the beads five times with $200 \mu \mathrm{L}$ of PBST. After the last washing step, collect the beads in $100 \mu \mathrm{L}$ of PBS (no Tween-20) and transfer to a clean new tube. Place the tube on the magnet.

9. Aspirate the PBS and add $100 \mu \mathrm{L}$ of non-reducing sample buffer. Remove $50 \mu \mathrm{L}$ and add 2-ME (5\%) to make reducing samples. Heat the samples to $95^{\circ} \mathrm{C}$ for $5 \mathrm{~min}$.

10. Separate the i.p. fraction from the beads on the magnet and collect it into a new tube.

11. Store samples at $-20^{\circ} \mathrm{C}$ until analysis.

\section{Preparation of IF Protein Samples for Mass Spectrometry Analysis}

1. Schedule a consultation with a proteomics expert prior to initiating a study since there is significant time and cost involved with mass spectrometry analysis.

2. Take special precautions to avoid contamination. Handle all gels with clean gloves and incubate in clean containers, washed only using $\mathrm{ddH}_{2} \mathrm{O}$ (avoid soap).

3. Run 20-50 $\mu \mathrm{L}$ of the HSE sample (from Sections 4 and 5) on an SDS-PAGE gel according to standard conditions.

4. Stain with a protein stain for $1 \mathrm{~h}$. Rinse multiple times and de-stain in $\mathrm{ddH}_{2} \mathrm{O}$ overnight. The IF protein bands should be easily visible after destaining.

5. Place the gel between plastic sheet protectors, scan and mark the bands that will be excised and sent for analysis.

6. Excise the IF protein bands using a new clean razor.

7. Place the gel bands in clean microcentrifuge tubes and transfer to a mass spectrometry facility. 


\section{Representative Results}

\section{A new rapid method for high salt-based extraction of IF proteins from multiple mouse tissues using lysing matrix.}

The traditional method ${ }^{25,26}$ of isolating the bulk of the intermediate filament protein fraction from epithelial tissue was modified here to include 9 different organs and a more rapid procedure for tissue lysis. While 3 manual homogenization steps are required for the traditional method, the modified procedure only has 1 manual homogenization step, which shortens the procedure by several hours, especially when processing more than 6 samples. Figure 1A shows a typical result of HSEs from 9 mouse tissues, while the table of expected proteins in the tissue and the molecular weight of each protein is shown in Figure 1B for comparison. Of note, the new automated method does not work well on pancreas and spleen; the traditional homogenization procedure works best for these tissues. This method should be useful for profiling IF proteins in a universal fashion across several tissues to assess organism-level responses to stress. As specific examples here, we show that IF proteins in liver (K8/K18) and brain (GFAP) from old mice are highly upregulated and undergo unique PTMs compared to the corresponding tissues in young mice.

\section{Liver K8 and K18 are strongly upregulated and undergo increased phosphorylation and lysine acetylation in livers from old mice.}

Figure 2 shows typical results from several of the analyses described in this protocol. Panel A depicts expression analysis of the two major IF genes in the liver, keratin 8 (KRT8) and keratin 18 (KRT18), which encode the IF proteins $\mathrm{K} 8$ and $\mathrm{K} 18$, respectively. Epithelial keratins are strongly upregulated under various stress conditions. In the result shown, this occurs during aging, since KRT8 is significantly upregulated in the livers of $24 \mathrm{~m}$ old mice compared to $3 \mathrm{~m}$ old mice. The results at the protein level are more striking, as observed by the dramatic increase in $\mathrm{K} 8$ monomer as well as high molecular mass complexes in the old $(24 \mathrm{~m})$ livers. Coomassie-based protein stain here serves as a loading control to ensure equal loading of protein across samples. Note that with total tissue lysates it is easy to overload protein on a gel, as it is in this case. Loading a smaller volume or diluting the sample further in sodium dodecyl sulfate (SDS) buffer will alleviate this problem (especially if it appears viscous and difficult to pipet). Panel C depicts a typical result from a liver High Salt Extract obtained using the automated protocol, demonstrating the strong enrichment of keratins 8 and 18 on the gel. The red lines demarcate the area that was excised and submitted for mass spectrometry analysis. In panel D the results of the mass spec analysis of the samples in panel C shows that K8 and K18 in the old liver have multiple phosphorylation and acetylation sites that are not present in the young liver.

\section{GFAP is strongly upregulated and lysine acetylated in the brains from old mice.}

Figure 3 demonstrates that the methods used to extract IFs from epithelia can also be used on non-epithelial tissue. Furthermore, the results reveal a general pattern for aging-dependent upregulation of IF genes and proteins. The GPCR result in Figure 2A reveals a 5-fold induction of GFAP mRNA in the brains of $24 \mathrm{~m}$ old mice compared to $3 \mathrm{~m}$ old mice. Figure 2B reveals total proteins present in the Triton X-100 fraction and the IF-enriched HSE. Note the increase in the band intensity at $50 \mathrm{kDa}$ marked by the arrow (corresponding to GFAP) in the old brain. Western blot analysis in Figure 2C further reveals the upregulation of GFAP and significant presence of GFAP monomer and potential high molecular mass complex in the Triton X-100 fraction (both marked by arrows). Western blot analysis of the same samples with a pan-acetyl lysine antibody shows that the antibody recognizes a band at $\sim 50 \mathrm{kDa}$ in the HSE of the old mouse brain and at $\sim 250 \mathrm{kDa}$ in the Triton X-100 fraction (Figure 2D). Immuno-enrichment of acetylated proteins from the Triton X-100 fractions reveals increased presence of GFAP protein in the lysate obtained from the old brain. Reducing and non-reducing conditions are shown to highlight GFAP monomer and high molecular mass complexes. Mass spectrometry analysis (similar to Figure 1) can be performed in this case to determine the site-specificity of the acetylated residues on GFAP in the old brain. 
A

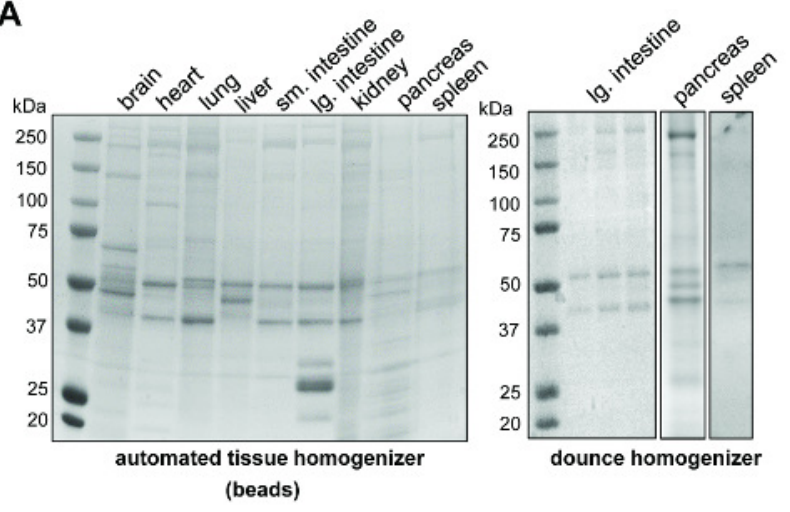

B

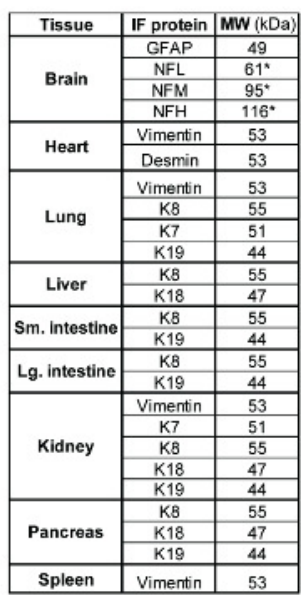

Figure 1: Automated lysis and extraction of IF proteins from multiple mouse tissues. (A) Coomassie-based gel stain of HSEs from the designated mouse tissues. The tissues shown were obtained from the same adult ( $3 \mathrm{~m}$ old $)$ male CBA mouse. Samples were processed as described in Section 5. Brain: note that NFL, NFM, and NFH are heavily phosphorylated ${ }^{27}$ and migrate slower than expected, at $\sim 70,145$, and $200 \mathrm{kDa}$, respectively. Heart: In addition to the $53 \mathrm{kDa}$ band corresponding to desmin and vimentin), heart samples also contain a $\sim 42 \mathrm{kDa}$ band, most likely representing actin, which is known to co-purify with desmin ${ }^{28}$. Large intestine: The identity of the prominent bands above 25 $\mathrm{kDa}$ that are co-extracted with $\mathrm{K} 8 / \mathrm{K} 18$ are not known, but these bands are not present if the tissues are processed using the traditional dounce homogenizer method. Pancreas and Spleen: Note that the automated homogenization is not suitable for isolation of keratins from pancreas and vimentin from spleen, presumably because of the sensitivity of the lysate to the slight increase in temperature during the pulse in the tissue lyser. (B) Table showing the major IF protein types present in the different tissues and their predicted molecular weight as a reference for panel A. Please click here to view a larger version of this figure.

A

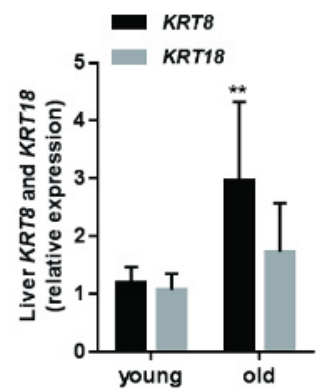

B

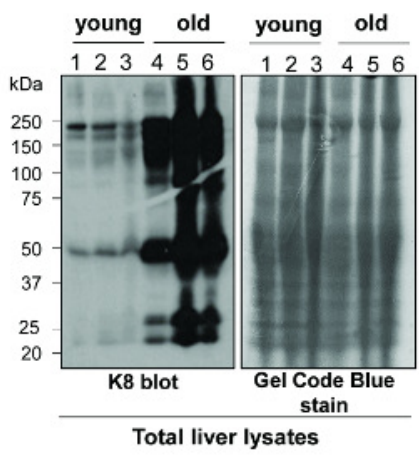

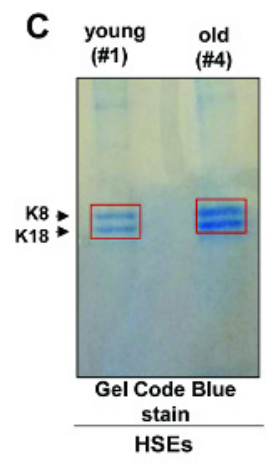

\begin{tabular}{|c|c|c|c|c|c|}
\hline Sample & Protein & Protein ID & Residues & Annotated Sequence & Modifications (confidence) \\
\hline Young & keratin 18 & P05784 & P05784 [180-189] & [R].KWDDTNITR.[L] & 1xAcetyl [K1(100)] \\
\hline Young & keratin 18 & P05784 & P05784 [27-46] & [R].VRPASSAASVYAGAGGSGSR.[]] & 1xPhospho [S5(100)] \\
\hline Old & keratin 18 & P05784 & P05784 [180-189] & [R].KWDDTNITR.[L] & 1xAcetyl [K1(100)] \\
\hline Old & keratin 18 & P05784 & P05784 [364-374] & [K].VKLEAEIATYR.[R] & 1xAcetyl [K2(100)] \\
\hline Old & keratin 18 & P05784 & P05784 [83-91] & [R].LASYLDKVK.[S] & 1xAcetyl [K7(99.7)] \\
\hline Old & keratin 18 & P05784 & P05784 [411-419] & [R].WSETNDTR.[M] & 1xPhospho [S3(100)] \\
\hline Old & keratin 18 & P05784 & P05784 [27-46] & [R].VRPASSAASWYAGAGGSGSR.[] & 1xPhospho [S17(100)] \\
\hline Old & keratin 18 & P05784 & P05784 [27-46] & [R].VRPASSAASWYAGAGGSGSR.[] & 1xPhospho [S5(100)] \\
\hline Old & keratin 18 & P05784 & P05784 [27-46] & [R].VRPASSAASVYAGAGGSGSR.[] & 1xPhospho [S6(100)] \\
\hline Old & keratin 18 & P05784 & P05784 [7-15] & [R].STTFSTNYR.[S] & 1xPhospho [T2(99.4)] \\
\hline Old & keratin 8 & P11679 & P11679 [399-407] & [R].KLLEGEESR.[IL] & 1xAcetyl [K1(100)] \\
\hline Old & keratin 8 & P11679 & P11679 [348-358] & [R].GEMAIKDAQTK.[L] & 1xAcetyl [K6(100)] \\
\hline Old & keratin 8 & P11679 & P11679 [24-32] & [R].SFTSGPGAR.[1] & 1xPhospho [S1(99.4)] \\
\hline Old & keratin 8 & P11679 & P11679 [335-347] & [R].ASLEAAIADAEQR.[G] & 1xPhospho [S2(100)] \\
\hline Old & keratin 8 & P11679 & P11679 [41-49] & [R].VGSSSSSFR.[G] & 1xPhospho [S3(100)] \\
\hline Old & keratin 8 & P11679 & $\mathrm{P} 11679$ [19-32] & [R].AFSSRSFTSGPGAR.[]] & 1xPhospho [S6(100)] \\
\hline
\end{tabular}

Figure 2: Molecular and biochemical differences in liver keratins from young and old mice. (A) Analysis of KRT8 and KRT8 mRNA using standard procedure (Protocol 1) reveals significant induction in KRT8 transcript in the livers from old mice. $\mathrm{n}=6$ for each condition (3 male and 3 female CBA mice were used per group). ${ }^{* *} p<0.01$; one-way ANOVA. (B) Total liver lysates were obtained from 3 young ( 3 months old) and 3 old (24 months old) male CBA mice using Protocol 2 and the samples were analyzed under non-reducing conditions. TS1 antibody was used to probe for K8 expression and Coomassie-based protein stain was used as a loading control. (C) High salt extracts from young and old mouse livers, corresponding to mice \#1 and \#4, respectively from panel B. The two arrows point to K8 and K18 on the gel and the red box indicates the part of the gel that was excised and submitted for mass spectrometry analysis. (D) PTM sites identified by mass spec analysis of the samples shown in C. Please click here to view a larger version of this figure. 
A

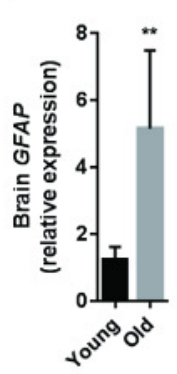

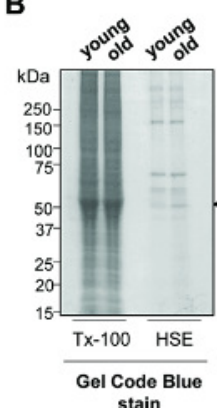

C

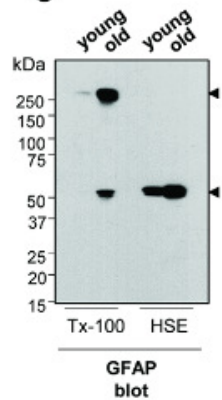

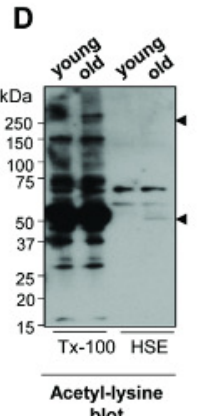

E

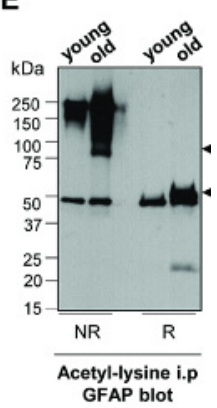

Figure 3: Molecular and biochemical differences in GFAP from brain of young and old mice. (A) Analysis of GFAP mRNA using standard procedure (Protocol 1) reveals significant induction in the brains from old mice. $n=6$ for each condition ( 3 male and 3 female CBA mice were used per group). ${ }^{* *} \mathrm{p}<0.01$; one-way ANOVA. (B) Coomassie-based protein stain of Triton X-100 and HSE fractions from brain tissue of young ( 3 months old) and old (24 months old) mouse. Note the increase in $\sim 50 \mathrm{kDa}$ GFAP band in HSE from old brain (arrow). (C) GFAP immunoblot (mouse monoclonal; GA5 clone) of the same samples as panel B. (D) Acetyl-lysine immunoblot (rabbit polyclonal; Abcam ab80178) of the same samples as in panel B. (E) GFAP blot after immunoprecipitation with acetyl-lysine antibody. Samples were analyzed under non-reducing (NR) and reducing $(R)$ conditions and arrows point to increase presence of GFAP in the immunoprecipitate from the old brain. Please click here to view a larger version of this figure.

\section{Discussion}

Methods that enable biochemical characterization of IF proteins can be useful to understand numerous pathophysiological phenomena in mammalian systems, since IF proteins are both markers and modulators of cellular and tissue stress ${ }^{29}$. The principle behind the current method is based on the initial procedures developed in the 1970s and 1980s to isolate, separate and reconstitute IF proteins from cells and tissues, generally employing low and high salt solutions and Triton-X100 detergent ${ }^{25,30,31,32,33,34,35}$. For historical insight into the studies that supported the biochemical isolation of IF proteins please see recent reviews ${ }^{36,37}$. The current method is based on more recent protocols developed for the study of simple epithelial keratins ${ }^{26}$. The advantage of the method is that it can serve as an initial step to enable investigators who are new to the IF field to effectively isolate IF proteins from most mammalian tissues. It represents a visual guide of related procedures that are widely used by investigators in the field to study IF protein regulation ${ }^{21,38}$.

This technique can be used to study the regulation and function of IFs in stress communication mechanisms between mammalian tissues ${ }^{39,40}$ It is becoming well-appreciated that stress in one tissue can affect the functioning of other tissues, for example under conditions of nutritional stress $^{41}$, protein misfolding ${ }^{42}$, metabolic stress ${ }^{43}$, and other changes. Of note, most of the work currently being done in this area is in Drosophila and $C$. elegans models, while studies on widespread stress responses in mammalian systems are lacking. As the major regulator of cellular stress $^{10}$, the IF system can unlock clues to organismal-level stress responses, which can have important disease implications. As such, the current protocol can be used to study global pathophysiological mechanisms in various mouse models of stress, injury and disease.

One limitation of the current technique is that the high salt extracts are considered "crude" IF preparations since they also contain other IFassociated proteins, such as plectin for example ${ }^{44}$. As shown previously, HSEs can be denatured in $8 \mathrm{M}$ urea buffer to obtain highly pure IF proteins that are capable of in vitro re-assembly in phosphate buffer ${ }^{44}$. After two such cycles of disassembly and re-assembly, the stoichiometry of IF proteins (isolated from HeLa cells) remained the same, whereas the urea treatment removed plectin ${ }^{44}$. During desmin purification, actin can be removed by solubilization of the HSE in acetic acid ${ }^{45}$. Whether additional purification steps should be included depends on the ultimate goal of the experiment. For example, if the goal is to characterize the assembly state and generate in vitro reconstituted IFs, the urea step is required to obtain highly pure IF proteins. On the other hand, if the goal is to identify context-dependent associations between IFs and other cellular proteins, then the "crude" preparations can be used. Interacting proteins can be identified by mass spectrometry using either in-gel digest for high abundance targets visible by gel stain, or in-solution digest for low abundance targets. Previous studies using immunoprecipitation of detergent-soluble IFs and HSEs containing IF proteins identified functionally important specific interaction between keratins $8 / 18$ and heat shock protein 70 (Hsp70), which is potentiated after heat stress ${ }^{46}$, the adaptor protein 14-3-3 after phosphorylation ${ }^{47}$, and K8/K18 Raf-1 kinase under normal physiologic conditions ${ }^{48}$ among others. The current protocol can enable similar studies on other IF proteins.

Use of the lysing matrix is a key modification from previous methods and should allow for rapid extraction of IFs from multiple tissues, with the exception of pancreas and spleen. The automation of the initial steps can be particularly useful for high-volume mouse experiments. For example, isolating IF proteins from 3 different tissues from 10 mice per condition (e.g. normal and some form of systemic stress or disease) will require processing of 60 individual tissues. Using the traditional manual method this would need to be done in batches and can take several days. However, using the automated method with lysing matrix, the procedure can be done in just a few hours. Critical steps of the procedure include: ensuring the sample stays cold throughout the procedure; incubation in high salt buffer for $1 \mathrm{~h}$ (step 4.5); using hot buffer and extensive vortexing to ensure complete resuspension of the pellet before analysis (step 4.8); and taking all precautions to avoid contamination of samples to be analyzed by mass spectrometry (step 7.2).

The major drawback to mass spectrometry-based identification of PTM sites is that it works very well for certain PTMs - phosphorylation and lysine acetylation being prime examples - but others, such as sumoylation are much more challenging ${ }^{49}$. Nevertheless, proteomics is a powerful tool for studying protein regulation in normal and diseased tissues. Agnetti et al. compiled a comprehensive up-to-date overview of cutting edge proteomic techniques currently in use to study various PTMs in the context of tissue-expressed proteins ${ }^{50}$. The purpose of the current method is to generate samples that can be applied for different types of analyses. For example, in vitro sumoylation can be performed on immuneprecipitated IF proteins, and overall sumoylation can be assessed on isolated IFs in HSE preparations using sumo-specific antibodies ${ }^{18,21}$. 
Therefore, the application of this method is not limited to generating samples only for mass spectrometry analysis but can be used to probe multiple IF properties using a variety of downstream techniques.

IF proteins are extensively regulated by numerous PTMs at conserved sites, resulting in altered solubility, filament assembly, and protein interactions ${ }^{17}$. Recent technological advances have unveiled the incredible magnitude, complexity, and disease significance of post-translational modifications (PTMs) on cellular proteins ${ }^{51,52,53}$. Improvement in detection methods for common PTMs, such as phosphorylation ${ }^{54}$ and acetylation $^{51}$, have yielded vast catalogs of data, but understanding their biological meaning - cracking the "PTM code" - is a major remaining challenge ${ }^{55,56}$. One way to assess the functional roles and relative significance of each PTM is to determine how well it is conserved across multiple members of the IF protein family. For example, identification of a novel phospho-tyrosine site on K8 revealed that this site is contained within a QYE motif found in essentially all cytoplasmic IF proteins and critical for regulating IF protein solubility and filament dynamics ${ }^{57}$. Importantly, mutation of the conserved tyrosine residue on GFAP to a negatively-charged "phosphomimic" aspartic acid (Y242D) causes Alexander Disease ${ }^{58}$. The representative data shown here demonstrate how two different tissue-specific IF protein types (K8 and GFAP) undergo similar pattern of upregulation and increased acetylation during aging, which may be an effect of altered metabolism ${ }^{22,51}$. This example illustrates the utility of the method in understanding the function of IF proteins on a global physiological scale.

\section{Disclosures}

The authors declare that they have no competing financial interests.

\section{Acknowledgements}

This work was supported by the NIH grants NIH R01 DK110355, DK093776 [N.T.S.], DK102450 [N.T.S.], and P30 DK034987 [to UNC-Chapel

Hill]. The authors thank Deekshita Ramanarayanan for assistance with qPCR and western blot experiments.

\section{References}

1. Eriksson, J. E. et al. Introducing intermediate filaments: from discovery to disease. J Clin Invest. 119 (7), $1763-1771$ (2009).

2. Lowery, J., Kuczmarski, E. R., Herrmann, H., \& Goldman, R. D. Intermediate Filaments Play a Pivotal Role in Regulating Cell Architecture and Function. J Biol Chem. 290 (28), 17145-17153 (2015).

3. Perez-Sala, D. et al. Vimentin filament organization and stress sensing depend on its single cysteine residue and zinc binding. Nat Commun. 67287 (2015).

4. Dialynas, G. et al. Myopathic lamin mutations cause reductive stress and activate the nrf2/keap-1 pathway. PLoS Genet. 11 (5), e1005231 (2015).

5. Hobbs, R. P. et al. Keratin-dependent regulation of Aire and gene expression in skin tumor keratinocytes. Nat Genet. (2015).

6. Chung, B. M., Rotty, J. D., \& Coulombe, P. A. Networking galore: intermediate filaments and cell migration. Curr Opin Cell Biol. 25 (5), 600-612 (2013).

7. Gruenbaum, Y., \& Aebi, U. Intermediate filaments: a dynamic network that controls cell mechanics. F1000Prime Rep. 654 (2014).

8. Omary, M. B. "IF-pathies": a broad spectrum of intermediate filament-associated diseases. J Clin Invest. 119 (7), 1756-1762 (2009).

9. Omary, M. B., Ku, N. O., Strnad, P., \& Hanada, S. Toward unraveling the complexity of simple epithelial keratins in human disease. $J$ Clin Invest. 119 (7), 1794-1805 (2009).

10. Toivola, D. M., Strnad, P., Habtezion, A., \& Omary, M. B. Intermediate filaments take the heat as stress proteins. Trends Cell Biol. 20 (2), 79-91 (2010).

11. Walther, D. M. et al. Widespread Proteome Remodeling and Aggregation in Aging C. elegans. Cell. 161 (4), 919-932 (2015).

12. David, D. C. et al. Widespread protein aggregation as an inherent part of aging in C. elegans. PLoS Biol. 8 (8), e1000450 (2010).

13. Windoffer, R., Beil, M., Magin, T. M., \& Leube, R. E. Cytoskeleton in motion: the dynamics of keratin intermediate filaments in epithelia. $J$ Cell Biol. 194 (5), 669-678 (2011).

14. Chou, C. F., Riopel, C. L., Rott, L. S., \& Omary, M. B. A significant soluble keratin fraction in 'simple' epithelial cells. Lack of an apparent phosphorylation and glycosylation role in keratin solubility. J Cell Sci. 105 ( Pt 2) 433-444 (1993).

15. Omary, M. B., Ku, N. O., Liao, J., \& Price, D. Keratin modifications and solubility properties in epithelial cells and in vitro. Subcell Biochem. 31 $105-140$ (1998).

16. Lowthert, L. A., Ku, N. O., Liao, J., Coulombe, P. A., \& Omary, M. B. Empigen BB: a useful detergent for solubilization and biochemical analysis of keratins. Biochem Biophys Res Commun. 206 (1), 370-379 (1995).

17. Snider, N. T., \& Omary, M. B. Post-translational modifications of intermediate filament proteins: mechanisms and functions. Nat Rev Mol Cell Biol. 15 (3), 163-177 (2014).

18. Snider, N. T., Weerasinghe, S. V., Iniguez-Lluhi, J. A., Herrmann, H., \& Omary, M. B. Keratin hypersumoylation alters filament dynamics and is a marker for human liver disease and keratin mutation. J Biol Chem. 286 (3), 2273-2284 (2011).

19. Eriksson, J. E. et al. Specific in vivo phosphorylation sites determine the assembly dynamics of vimentin intermediate filaments. $J$ Cell Sci. 117 (Pt 6), 919-932 (2004).

20. Sahlgren, C. M. et al. Mitotic reorganization of the intermediate filament protein nestin involves phosphorylation by cdc2 kinase. J Biol Chem. 276 (19), 16456-16463 (2001).

21. Snider, N. T., \& Omary, M. B. Assays for Posttranslational Modifications of Intermediate Filament Proteins. Methods Enzymol. 568 113-138 (2016)

22. Snider, N. T. et al. Glucose and SIRT2 reciprocally mediate the regulation of keratin 8 by lysine acetylation. J Cell Biol. 200 (3), 241-247 (2013).

23. Danneman, P., Suckow, M. A., Brayton, C., \& Suckow, M. A. The laboratory mouse. 2 nd edn CRC Press, (2013).

24. Weiss, W., Weiland, F., \& Gorg, A. Protein detection and quantitation technologies for gel-based proteome analysis. Methods Mol Biol. 564 59-82 (2009) 
25. Achtstaetter, T., Hatzfeld, M., Quinlan, R. A., Parmelee, D. C., \& Franke, W. W. Separation of cytokeratin polypeptides by gel electrophoretic and chromatographic techniques and their identification by immunoblotting. Methods Enzymol. 134 355-371 (1986).

26. Ku, N. O. et al. Studying simple epithelial keratins in cells and tissues. Methods Cell Biol. 78 489-517 (2004).

27. Julien, J. P., \& Mushynski, W. E. Multiple phosphorylation sites in mammalian neurofilament polypeptides. J Biol Chem. 257 (17), 10467-10470 (1982).

28. Hubbard, B. D., \& Lazarides, E. Copurification of actin and desmin from chicken smooth muscle and their copolymerization in vitro to intermediate filaments. J Cell Biol. 80 (1), 166-182 (1979).

29. Ku, N. O., Strnad, P., Bantel, H., \& Omary, M. B. Keratins: Biomarkers and modulators of apoptotic and necrotic cell death in the liver. Hepatology. 64 (3), 966-976 (2016).

30. Huiatt, T. W., Robson, R. M., Arakawa, N., \& Stromer, M. H. Desmin from avian smooth muscle. Purification and partial characterization. $J$ Biol Chem. 255 (14), 6981-6989 (1980).

31. Zackroff, R. V., \& Goldman, R. D. In vitro assembly of intermediate filaments from baby hamster kidney (BHK-21) cells. Proc Natl Acad Sci U $S$ A. 76 (12), 6226-6230 (1979).

32. Franke, W. W., Schmid, E., Osborn, M., \& Weber, K. The intermediate-sized filaments in rat kangaroo PtK2 cells. II. Structure and composition of isolated filaments. Cytobiologie. 17 (2), 392-411 (1978).

33. Small, J. V., \& Sobieszek, A. Studies on the function and composition of the 10-NM(100-A) filaments of vertebrate smooth muscle. J Cell Sci. 23 243-268 (1977).

34. Dahl, D., \& Bignami, A. Glial fibrillary acidic protein from normal human brain. Purification and properties. Brain Res. 57 (2), $343-360$ (1973).

35. Steinert, P. M., Idler, W. W., \& Zimmerman, S. B. Self-assembly of bovine epidermal keratin filaments in vitro. J Mol Biol. 108 (3), $547-567$ (1976).

36. Goldman, R. D., Cleland, M. M., Murthy, S. N., Mahammad, S., \& Kuczmarski, E. R. Inroads into the structure and function of intermediate filament networks. J Struct Biol. 177 (1), 14-23 (2012).

37. Oshima, R. G. Intermediate filaments: a historical perspective. Exp Cell Res. 313 (10), 1981-1994 (2007).

38. Mashukova, A., Forteza, R., \& Salas, P. J. Functional Analysis of Keratin-Associated Proteins in Intestinal Epithelia: Heat-Shock Protein Chaperoning and Kinase Rescue. Methods Enzymol. 569 139-154 (2016).

39. Schinzel, R., \& Dillin, A. Endocrine aspects of organelle stress-cell non-autonomous signaling of mitochondria and the ER. Curr Opin Cell Biol. 33 102-110 (2015)

40. Taylor, R. C., Berendzen, K. M., \& Dillin, A. Systemic stress signalling: understanding the cell non-autonomous control of proteostasis. Nat Rev Mol Cell Biol. 15 (3), 211-217 (2014).

41. Lemieux, G. A. et al. Kynurenic acid is a nutritional cue that enables behavioral plasticity. Cell. 160 (1-2), 119-131 (2015).

42. Oosten-Hawle, P., Porter, R. S., \& Morimoto, R. I. Regulation of organismal proteostasis by transcellular chaperone signaling. Cell. 153 (6), 1366-1378 (2013).

43. Ulgherait, M., Rana, A., Rera, M., Graniel, J., \& Walker, D. W. AMPK modulates tissue and organismal aging in a non-cell-autonomous manner. Cell Rep. 8 (6), 1767-1780 (2014).

44. Aynardi, M. W., Steinert, P. M., \& Goldman, R. D. Human epithelial cell intermediate filaments: isolation, purification, and characterization. $J$ Cell Biol. 98 (4), 1407-1421 (1984).

45. Shea, J. M. et al. Purification of desmin from adult mammalian skeletal muscle. Biochem J. 195 (2), $345-356$ (1981).

46. Liao, J., Lowthert, L. A., Ghori, N., \& Omary, M. B. The 70-kDa heat shock proteins associate with glandular intermediate filaments in an ATPdependent manner. J Biol Chem. 270 (2), 915-922 (1995).

47. Liao, J., \& Omary, M. B. 14-3-3 proteins associate with phosphorylated simple epithelial keratins during cell cycle progression and act as a solubility cofactor. J Cell Biol. 133 (2), 345-357 (1996).

48. Ku, N. O., Fu, H., \& Omary, M. B. Raf-1 activation disrupts its binding to keratins during cell stress. J Cell Biol. 166 (4), $479-485$ (2004).

49. Hendriks, I. A., \& Vertegaal, A. C. A comprehensive compilation of SUMO proteomics. Nat Rev Mol Cell Biol. 17 (9), $581-595$ (2016).

50. Agnetti, G., Lindsey, M. L., \& Foster, D. B. Manual of cardiovascular proteomics. Springer, (2016).

51. Choudhary, C., Weinert, B. T., Nishida, Y., Verdin, E., \& Mann, M. The growing landscape of lysine acetylation links metabolism and cell signalling. Nat Rev Mol Cell Biol. 15 (8), 536-550 (2014).

52. Herhaus, L., \& Dikic, I. Expanding the ubiquitin code through post-translational modification. EMBO Rep. 16 (9), $1071-1083$ (2015).

53. Dephoure, N., Gould, K. L., Gygi, S. P., \& Kellogg, D. R. Mapping and analysis of phosphorylation sites: a quick guide for cell biologists. Mol Biol Cell. 24 (5), 535-542 (2013).

54. Choudhary, C., \& Mann, M. Decoding signalling networks by mass spectrometry-based proteomics. Nat Rev Mol Cell Biol. 11 (6), $427-439$ (2010).

55. Creixell, P., \& Linding, R. Cells, shared memory and breaking the PTM code. Mol Syst Biol. 8598 (2012).

56. Minguez, P. et al. Deciphering a global network of functionally associated post-translational modifications. Mol Syst Biol. 8 599 (2012).

57. Snider, N. T., Park, H., \& Omary, M. B. A conserved rod domain phosphotyrosine that is targeted by the phosphatase PTP1B promotes keratin 8 protein insolubility and filament organization. J Biol Chem. 288 (43), 31329-31337 (2013).

58. Gorospe, J. R. et al. Molecular findings in symptomatic and pre-symptomatic Alexander disease patients. Neurology. 58 (10), 1494-1500 (2002). 